\title{
APLIKASI SISTEM PAKAR DALAM PEMILIHAN METODE PERBAIKAN DAYA DUKUNG TANAH LUNAK PADA KONSTRUKSI JALAN
}

\author{
(Application Of Expert Sytems In Selecting Metohds For Improving The Bearing Capacity Of Soft Soil In \\ Road Construction)
}

\author{
Alissia Westy Putri ${ }^{1}$, Trihono Kadri ${ }^{2}$ \\ ${ }^{1}$ Magister Teknik Sipil FTSP - Usakti \\ ${ }^{2}$ Magister Teknik Sipil FTSP - Usakti
}

\begin{abstract}
Korespodensi Penulis : Taman Royal 3. Cluster Albasi 2 No.10 Cipondoh Kota Tangerang
E-mail: alissiawesty@gmail.com
\end{abstract}

\begin{abstract}
ABSTRAK
Tahap awal pembangunan konstruksi jalan hal yang harus diperhatikan adalah tanah dasar atau tanah asli di wilayah yang akan dibangun. Tanah lunak merupakan permasalahan dalam pembangunan konstruksi karena memiliki daya dukung tanah yang rendah. Perbaikan tanah lunak merupakan salah satu cara dalam meningkatkan daya dukung tanah. Untuk mengetahui metode yang efisien digunakan dalam perbaikan daya dukung tanah lunak memerlukan seorang ahli atau pakar dibidang tanah. Sistem pakar merupakan suatu program komputer yang berusaha menirukan proses dari seorang ahli pakar dalam memecahkan suatu permasalahan. Tujuan pengembangan sistem pakar adalah untuk mensubsitusikan pengetahuan ahli pakar ke dalam bentuk sistem sehingga dapat digunakan oleh masyarakat untuk memecahkan masalah tertentu. Sistem pakar ini dirancang dengan beberapa tahapan diantaranya wawancara ahli pakar tanah, akuisisi pengetahuan, tabel keputusan, analisa metode forward chaining, implementasi dan pengujian keakuratan aplikasi sistem pakar. Aplikasi sistem pakar dalam pemilihan metode perbaikan daya dukung tanah lunak pada konstruksi jalan berbasis web localhost dalam pengolahan data menggunakan javascript dan base data menggunakan HTML berupa aturan (rule based reasioning) dengan metode inferensi forward chaining yang dimaksud untuk membantu user dalam penggunaan aplikasi sistem pakar. Hasil pengujian terhadap aplikasi sistem pakar dinyatakan baik dengan tingkat akurasi $86,7 \%$.
\end{abstract}

Kata kunci : Pengembangan Sistem Pakar, Tanah Lunak, Metode Perbaikan Daya Dukung Tanah Lunak, HTML, Forward Chaining.

\section{ABSTRACT}

The initial stage of road construction, the thing that must be considered is the subgrade or original land in the area to be built. Soft soil is a problem in construction construction because it has a low soil bearing capacity. Improvement of soft soil is one way to increase soil bearing capacity. To find out the efficient method used in improving the bearing capacity of soft soil requires an expert or expert in the field of land. An expert system is a computer program that attempts to mimic the process of an expert in solving a problem. The purpose of developing expert systems is to substitute expert expert knowledge into a system so that it can be used by the public to solve certain problems. This expert system is designed with several stages including interviews with soil experts, knowledge acquisition, decision tables, forward chaining method analysis, implementation and testing of the accuracy of expert system applications. Expert system application in selecting the method of improving soft soil bearing capacity on localhost web-based road construction in data processing using javascript and base data using HTML in the form of rules (rule based reasioning) with the forward chaining inference method which is intended to assist users in using expert system applications. The test results of the expert system application are stated to be good with an accuracy rate of $86.7 \%$.

Keywords: summary, paper, Indonesian (minimal 3 keywords or phrases separated with comma, Times new roman 11) 


\section{PENDAHULUAN}

Tahap awal pembangunan konstruksi hal yang harus di perhatikan adalah tanah dasar atau tanah asli diwilayah yang akan dibangun. Untuk mendirikan bangunan konstruksi membutuhkan pondasi yang kuat. Agar diperoleh pondasi yang kuat, pondasi harus terletak pada tanah yang mampu menahan beban konstruksi. Pada kenyataannya tanah yang ditemukan dilapangan tidak semuanya baik menerima beban. Tanah lunak merupakan permasalahan dalam pembangunan konstruksi karena memiliki daya dukung yang rendah.

Perbaikan tanah lunak merupakan salah satu cara dalam meningkatkan daya dukung tanah. Ada beberapa macam metode perbaikan tanah. Untuk mengetahui metode yang efisien digunakan perlu seseorang ahli pakar di bidang tanah. Sistem pakar merupakan suatu program komputer yang berusaha menirukan proses dari ahli pakar. Tujuan pengembangan sistem pakar adalah untuk mensubsitusika pengetahuan ahli pakar ke dalam bentuk sistem sehingga dapat digunakan oleh masyarakat untuk memecahkan masalah tertentu. Salah satu implementasi yang diterapkan sistem pakar dibidang konstruksi yaitu aplikasi sistem pakar dalam pemilihan metode perbaikan daya dukung tanah lunak pada konstruksi jalan.

\section{STUDI PUSTAKA}

Tanah lunak merupakan tanah-tanah yang jika tidak dikenali dan diselidiki secara berhati-hati dapat menyebabkan masalah ketidakstabilan dan penurunan jangka panjang yang tidak dapat ditolerir; tanah tersebut mempunyai kuat geser yang rendah dan kompresibilitas yang tinggi (Geoteknik 1, 2001). Perbaikan daya dukung tanah adalah kumpulan upaya-upaya yang dapat dilakukan terhadap tanah yang memiliki karakteristik teknis (engineering properties) yang bermutu rendah menjadi material yang layak digunakan sebagai material konstruksi (mempunyai karakteristik teknis yang lebih baik). Sistem pakar sebagai suatu program komputer yang memiliki kemampuan intelligence, yang menggunakan pengetahuan dan prosedur inferensi untuk menyelesaikan suatu masalah rumit yang membutuhkan kemampuan seorang pakar untuk memberikan solusi (Gevarter, 1982).

\section{A. Akuisisi Pengetahuan}

Pengetahuan sistem pakar diorganisasikan sedemikian rupa sehingga pengetahuan tentang domain masalah dipisahkan dari pengetahuan sistem lainnya, seperti pengetahuan tentang cara memecahkan suatu masalah. Kumpulan pengetahuan tentang domain masalah disebut basis pengetahuan, sedangkan pengetahuan untuk memecahkan masalah berada dalam mesin inferensi.

B. Tabel Keputusan

Perancangan tabel keputusan dilakukan dengan cara mengidentifikasi rule dari knowledge pakar kemudian memasukkan rule ke dalam alur penelusuran untuk ditelusuri.

C. Metode Forward Chaining

Metode Forward chaining merupakan metode inference yang melakukan penalaran dari suatu masalah kepada solusinya, karena inference dimulai dengan informasi yang tersedia dan baru konklusi diperoleh. Jika klausa premis sesuai dengan situasi (bernilai true), maka proses akan menyatakan konklusi (Durkin.J, 1994). 


\section{METODE PENELITIAN}

Penelitian ini dilakukan di proyek jalan tol Kayu Agung - Palembang Betung Seksi 2 STA 0+098 - $0+300$ dan proyek jalan tol Terbanggi Besar - Kayu Agung Lampung STA 110+820 - 110+860.

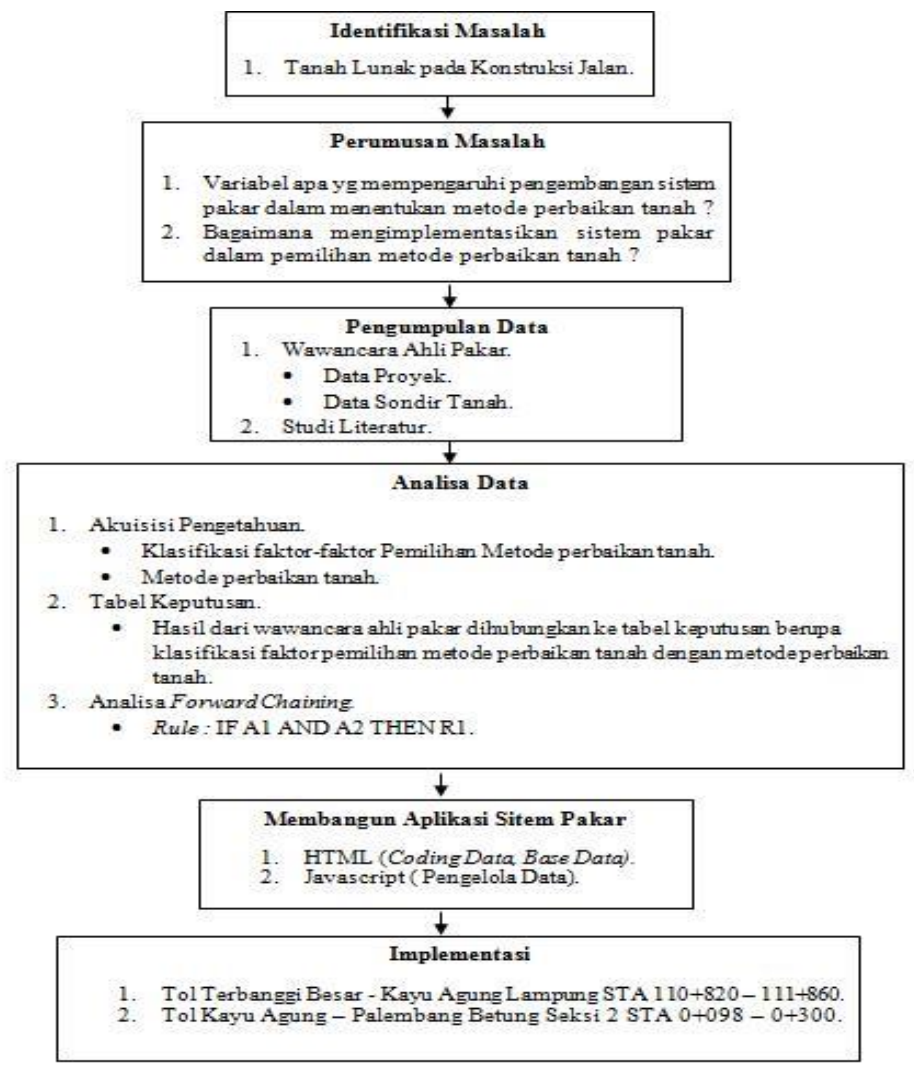

Gambar 1. Diagram Alur Metode Penelitian

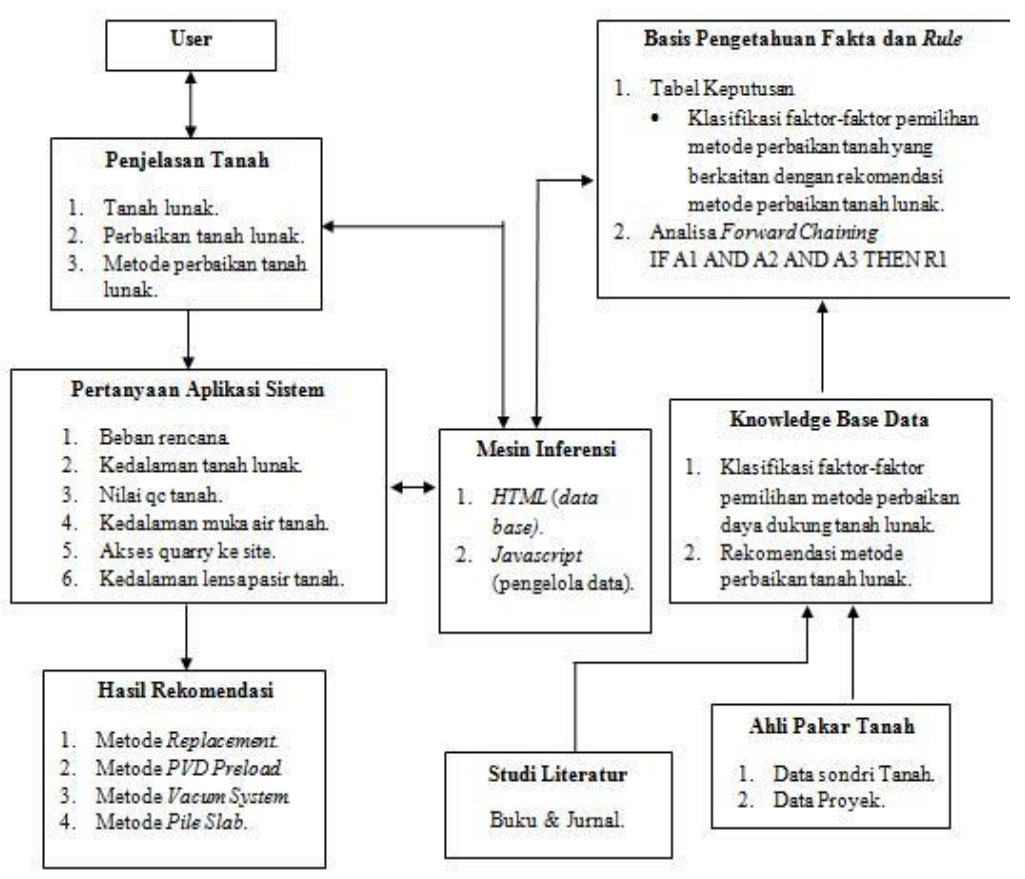

Gambar 2. Diagram Alur Aplikasi Sistem Pakar 


\section{HASIL DAN PEMBAHASAN}

1. Tabel Keputusan

Tabel 1. Tabel Keputusan

\begin{tabular}{|c|c|c|c|c|c|}
\hline \multirow{2}{*}{$\begin{array}{c}\text { Kode } \\
\mathrm{A}\end{array}$} & \multirow{2}{*}{$\begin{array}{l}\begin{array}{l}\text { Klasifikasi Faktor Pemlihan } \\
\text { Metode }\end{array} \\
\text { Klasifikasi Beban Rencana }\end{array}$} & \multicolumn{4}{|c|}{$\begin{array}{l}\text { Metode Perbaikan Tanah Lunak } \\
\text { Pada Konstruksi Jalan }\end{array}$} \\
\hline & & P1 & P2 & P3 & P4 \\
\hline A1 & Beban Rencana $1-20 \mathrm{Kn} / \mathrm{m} 2$ & $\sqrt{ }$ & $\sqrt{ }$ & $\sqrt{ }$ & $\sqrt{ }$ \\
\hline $\mathrm{A} 2$ & Beban Rencana $21-40 \mathrm{Kn} / \mathrm{m} 2$ & $\sqrt{ }$ & $\sqrt{ }$ & $\sqrt{ }$ & $\sqrt{ }$ \\
\hline $\mathrm{A} 3$ & Beban Rencana $40-50 \mathrm{Kn} / \mathrm{m} 2$ & $\sqrt{ }$ & $\sqrt{ }$ & $\sqrt{ }$ & $\sqrt{ }$ \\
\hline B & $\begin{array}{l}\text { Klasifikasi Kedalaman Tanah } \\
\text { Lunak }\end{array}$ & & & & \\
\hline B1 & Kedalaman TanahLunak $1-4 \mathrm{~m}$ & $\sqrt{ }$ & & & \\
\hline B2 & Kedalaman TanahLunak $5-30 \mathrm{~m}$ & & $\sqrt{ }$ & $\sqrt{ }$ & \\
\hline B3 & Kedalaman TanahLunak $>31 \mathrm{~m}$ & & & & $\sqrt{ }$ \\
\hline C & Klasifikasi Nilai qc Tanah & & & & \\
\hline $\mathrm{C} 1$ & Nilai qc Pada Tanah $0-5 \mathrm{~kg} / \mathrm{cm} 2$ & $\sqrt{ }$ & $\sqrt{ }$ & $\sqrt{ }$ & $\sqrt{ }$ \\
\hline $\mathrm{C} 1$ & Nilai qc Pada Tanah $6-10 \mathrm{~kg} / \mathrm{cm} 2$ & $\sqrt{ }$ & $\sqrt{ }$ & $\sqrt{ }$ & $\sqrt{ }$ \\
\hline D & Klasifikasi NSPT Pada Tanah & & & & \\
\hline D1 & NSPT $0-2$ & $\sqrt{ }$ & $\sqrt{ }$ & $\sqrt{ }$ & $\sqrt{ }$ \\
\hline D2 & NSPT $3-4$ & $\sqrt{ }$ & $\sqrt{ }$ & $\sqrt{ }$ & $\sqrt{ }$ \\
\hline E & $\begin{array}{l}\text { Klasifikasi Kedalaman Muka Air } \\
\text { Tanah }\end{array}$ & & & & \\
\hline E1 & Kedalaman Muka Air Tanah 1 - 3m & $\sqrt{ }$ & $\sqrt{ }$ & $\sqrt{ }$ & $\sqrt{ }$ \\
\hline E2 & KedalamanMuka Air Tanah 4-6m & & $\sqrt{ }$ & & $\sqrt{ }$ \\
\hline E3 & Kedalaman Muka Air Tanah $>7 \mathrm{~m}$ & & & & $\sqrt{ }$ \\
\hline $\mathbf{F}$ & Klasifikasi Jarak Quarry ke Site & & & & \\
\hline F1 & Jarak $0-40 \mathrm{~km}$ & $\sqrt{ }$ & $\sqrt{ }$ & $\sqrt{ }$ & $\sqrt{ }$ \\
\hline F2 & Jarak $41-80 \mathrm{~km}$ & & & $\sqrt{ }$ & $\sqrt{ }$ \\
\hline $\mathrm{F}_{3}$ & Jarak $>81 \mathrm{~km}$ & & & & $\sqrt{ }$ \\
\hline
\end{tabular}

2. Analisa Metode Forward Chaining

Analisis inferensi Forward chaining dapat berbentuk sebuah rule. Dalam perancangan sistem pakar ini menggunakan metode penalaran forward chaining (pelacakan maju) yaitu dimulai dari sekumpulan fakta-fakta tentang faktor pemilihan metode perbaikan daya dukung tanah lunak yang diberikan oleh user sebagai masukan ke dalam sistem, sampai tujuan akhir berupa rekomendasi pemilihan metode perbaikan daya dukung tanah lunak pada pembangunan konstruksi jalan.

3. Analisa Hasil Pengujian

Pengujian Kelayakan Sistem. Pengujian dilakukan terhadap 10 respoden yang bekerja di perusahaan bidang soil improvement dan kontraktor jalan yaitu dengan menjalankan program aplikasi yang dilakukan pengguna.

Tabel 2. Penilaian Kelayakan Aplikasi Sistem Pakar

\begin{tabular}{|c|c|c|c|c|c|}
\hline$N_{0}$ & $\begin{array}{c}\text { Sangat } \\
\text { Kurang }\end{array}$ & Kurang & Cukup & Baik & $\begin{array}{c}\text { Sangat } \\
\text { Baik }\end{array}$ \\
\hline 1 & & & 4 & 1 & 5 \\
\hline 2 & & 1 & 2 & 5 & 2 \\
\hline 3 & & & 4 & 1 & 5 \\
\hline 4 & & & 4 & 1 & 5 \\
\hline 5 & & 1 & 1 & 5 & 3 \\
\hline 6 & & & 4 & 2 & 4 \\
\hline 7 & & & 4 & 4 & 2 \\
\hline 8 & & & & 5 & 5 \\
\hline 9 & & 1 & 3 & 2 & 4 \\
\hline 10 & & & 4 & 2 & 4 \\
\hline Jumlah & 0 & 3 & 30 & 28 & 39 \\
\hline
\end{tabular}

Jika total skor penilaian responden diperoleh angka 403, maka penilaian responden terhadap pengujian kelayakan aplikasi ini : 
$\overline{500} \times 100 \%=80,6 \%$

Hal tersebut dapat disimpulkan bahwa kelayakan aplikasi sistem pakar dengan nilai 80,6\% .

Pengujian keakuratan sistem pakar dilakukan terhadap 5 responden ahli pakar tanah dan 5 responden yang bekerja di konstruksi jalan. Pengujian dilakukan sebagai pembanding dari jawaban 5 ahli pakar tanah dengan 5 responden yang menggunakan aplikasi sistem pakar dalam menentukan metode perbaikan daya dukung tanah lunak pada konstruksi jalan. Ada 2 proyek yang belum menentukan metode perbaikan daya dukung tanah lunak pada konstruksi jalan yaitu project jalan tol Kayu Agung - Palembang Betung Seksi 2 STA 0+098 - 0+300 dan proyek jalan tol Terbanggi Besar - Kayu Agung Lampung STA 110+820 - 110+860.

Tabel 3. Tabel Pengujian Keakuratan Aplikasi

\begin{tabular}{|c|c|c|c|}
\hline \multicolumn{4}{|c|}{$\begin{array}{l}\text { Project Jalan Tol Kayu Agung - Palembang Betung Seksi } 2 \text { STA } 0+098 \text { - } \\
\qquad \begin{array}{l}0+300 \\
\text { - }\end{array}\end{array}$} \\
\hline No & Nama Metode & Ahli Pakar & Aplikasi Sistem Pakar \\
\hline 1 & $0+098$ & 5 & 5 \\
\hline 2 & $0+138$ & 5 & 5 \\
\hline 3 & $0+178$ & 5 & 5 \\
\hline 4 & $0+218$ & 5 & 5 \\
\hline 5 & $0+258$ & 5 & 5 \\
\hline 6 & $0+020$ & 5 & 5 \\
\hline 7 & $0+060$ & 5 & 5 \\
\hline 8 & $0+100$ & 5 & 5 \\
\hline 9 & $0+140$ & 5 & 5 \\
\hline 10 & $0+180$ & 5 & 5 \\
\hline 11 & $0+220$ & 5 & 5 \\
\hline 12 & $0+260$ & 5 & 5 \\
\hline 13 & $0+300$ & 5 & 5 \\
\hline
\end{tabular}

\begin{tabular}{|c|c|c|c|}
\hline \multicolumn{4}{|c|}{ Project Jalan Tol Terbangi Besar- Kayu Agung Lampung STA 110+820 } \\
$-110+860$
\end{tabular}

Project Jalan Tol Kayu Agung - Palembang Betung Seksi 2 STA 0+098 - 0+300 yang mempunyai 13 STA dan Project Jalan Tol Terbanggi Besar - Kayu Agung Lampung STA 110+820 - 110+860 yang mempunyai 2 STA, jika direkapitulasi ada 15 STA. ada 2 STA pada Project Jalan Tol Terbanggi Besar - Kayu Agung Lampung STA 110+820 - 110+860 yang menghasilkan kegagalan dalam aplikasi sistem pakar. Adapun untuk nilai akurasi pengujian tersebut adalah $65 / 75 \times 100 \%=86,7 \%$.

\section{KESIMPULAN}

Dari sistem pakar yang dibangun telah dihasilkan suatu sistem yang dapat menghasilkan proses dalam memberikan rekomendasi awal dalam pemilihan metode perbaikan daya dukung tanah lunak pada pembangunan konstruksi jalan. Hasil dari pengujian keakuratan aplikasi sistem pakar terhadap 2 proyek pembangunan jalan yaitu project jalan tol Kayu Agung - Palembang Betung Seksi 2 STA 0+098 - 0+300 ada 13 STA dan proyek jalan tol Terbanggi Besar - Kayu Agung Lampung STA 110+820 - 110+860 ada 2 STA. Ada 2 STA pada Project Jalan Tol Terbanggi Besar - Kayu Agung Lampung STA 110+820 - 110+860 yang menghasilkan kegagalan dalam aplikasi sistem pakar. Nilai Akurasi dihitung dengan membandingkan nilai keberhasilan dalam mendeteksi metode perbaikan daya dukung tanah lunak pada konstruksi jalan. Nilai akurasi yang di dapat sebesar $86,7 \%$. 


\section{DAFTAR PUSTAKA}

Arhami, Muhammad. (2005). Konsep Dasar Sistem Pakar. Penerbit Andi,

Jogjakarta Aziz Jaya Putra (HATTI), Perbaikan Tanah Lunak Brosur, PT.

Geostructure Dynamics, Jakarta.

Darwis.2018. Dasar - Dasar Teknik Perbaikan Tanah. Makasar.

Durkin, J. (1994). Expert System Design and Development. New Jersey: Prentice Hall International Inc.

Dipohusodo, Istimawan.1996. Manajemen Proyek \& Konstruksi.Kanisius. Jogjakarta.

Diklat Penanganan Tanah Problematika Pada Struktur Jalan, PUPR

Empy, Rudy Satya, 2002, Rekomendasi tindakan koreksi pada pengelolaan overhead lapangan dalam pengendalian biaya proyek dengan menggunakan expert system, Fakultas Tenik Sipil, UniversitasIndonesia.

Ervianto, I.W. (2005). Manajemen Proyek Konstruksi Edisi Revisi. Yogyakarta.Andi.

Gevarter, 1982. IFAC Information Control Problems in Manufacturing Technology. Maryland, USA

Kusumadewi, S., 2003. Artificial Intelligence (Teknik dan Aplikasinya). Yogyakarta Graha Ilmu.

Malay, Junaidey, 2014. Pengembangan Sistem Pada Pemilihan Bangunan Pengaman Pantai Banten, Fakultas Teknik, Universitas Trisakti.

Mohan, S. (1990), "Expert System Application in Construction Management and Engineering."

Mockler, j.r., 1989. “Knowledge Based System For Management Decisions”, Singapore, Prentice

Hall Nazir. Moh. 1983. Metode Penelitian. Jakarta: Ghalia Indonesia

Yarni, Novi. 2012. Sistem pakar penyakit tulang pada manusia menggunakan metode dempster-shafer berbasis wap dengan wml dan php diRSUD

Rich, E. (1983). Artificial Intelligence. Tokyo, Japan: Mcgraw-Hill

Tanimoto, S.L. (1987). The Elements of Artificial Inteligence. Maryland: Computer Science Press

Sanjaya R, dan W. Onno. 2001. Buku Pintar Internet Membuat Aplikasi W@ P Dengan PHP. Jakarta: Elex Media Komputindo.

Staugaard, A.C. (1987). Robotics and AI: An Introduction to Applied Machine Intelligence. New Jersey

Terazeghi, K., Peck, R. B. 1987.Mekanika Tanah Dalam Praktek Rekayasa. Pernerbit Erlangga, Jakarta 